\title{
Endometriosis - A Chameleon: Patients' Perception of Clinical Symptoms, Treatment Strategies and Their Impact on Symptoms
}

Endometriose ein Chamäleon - subjektive Beurteilung von Patientinnen bezüglich der klinischen Symptomatik, Behandlungsstrategien und deren Einfluss auf die Beschwerdesymptomatik

Authors

Affiliations
P. Wimberger ${ }^{1}$, N. Grübling ${ }^{1}$, A. Riehn ${ }^{1}$, M. Furch ${ }^{1}$, J. Klengel ${ }^{2}$, M. Goeckenjan ${ }^{1}$

${ }^{1}$ Gynecology and Obstetrics, Technische Universität Dresden, Dresden

2 Praxis für Gynäkologie und Geburtshilfe, Dresden
Key words
- endometriosis
infertility
- sterility
- endocrine treatment
- adenomyosis uteri interna
- compliance

Schlüsselwörter
Endometriose
Infertilität
Sterilität
endokrine Therapie
Adenomyosis uteri interna
- Compliance

received 20.7.2014

revised 23.8.2014

accepted 24.8.2014

\section{Bibliography}

Dol http://dx.doi.org/

10.1055/s-0034-1383168

Geburtsh Frauenheilk 2014; 74:

940-946 (c) Georg Thieme

Verlag KG Stuttgart - New York . ISSN 0016-5751

\section{Correspondence}

Prof. Pauline Wimberger,

PhD, MD

Technische Universität Dresden

Gynecology and Obstetrics

Fetscherstraße 74

01307 Dresden

pauline.wimberger@

uniklinikum-dresden.de

\section{Abstract \\ $\nabla$}

Introduction: Endometriosis is a chronic disease with differing clinical presentations. Treatment strategies depend mainly on clinical presentation and patient lifestyle. In women newly diagnosed with endometriosis, it is often difficult to understand the pathophysiologic origin, the potential individual impairment due to disease and the different treatment options. Compliance with the selected treatment is therefore often not optimal. Material and Methods: In a descriptive study, data of 51 women with endometriosis (mean age 36.2 years \pm 11.3 ) were analyzed according to the predominant clinical presentation: asymptomatic disease, disease with typical symptoms, ovarian cysts or infertility.

Results: More than $50 \%$ of patients ascribed a therapeutic benefit to surgical intervention or endocrine treatment, especially women in the subgroup with dysmenorrhea who received combined treatment. It should be noted that in the group of women facing infertility, more than half stated that they could not decide on the value of diagnostic and therapeutic reproductive medicine. Nevertheless, more than half of the women in this group became pregnant within two years after the initial diagnosis.

Discussion: When deciding on the best treatment strategy for endometriosis, it is important to take account of potential pain and infertility. Women's perception of endometriosis will vary depending on their symptoms, the time of diagnosis and their lifestyle. Offering continuous information on clinical aspects and manifestations of the disease may improve treatment outcomes. Personalized counseling is an essential part of the clinical management of the disease.

\section{Zusammenfassung \\ $\nabla$}

Einleitung: Endometriose ist eine chronische Erkrankung mit unterschiedlichem klinischem Erscheinungsbild. Die Behandlungsoptionen sind abhängig von Symptomatik und Lebenssituation der Patientin. Frauen haben Schwierigkeiten, die Gesamtheit der pathophysiologischen Vorgänge, die verschiedenen Therapieoptionen und die mögliche Beeinträchtigung der Gesundheit bei Diagnosestellung zu verstehen. Daher ist häufig die Compliance bez. der vorgeschlagenen Therapie nicht optimal.

Material und Methode: In einer deskriptiven Studie wurden Daten von 51 Frauen mit Endometriose (mittleres Alter 36,2 \pm 11,3 Jahre) zur subjektiven Beurteilung der Erkrankung in Abhängigkeit des führenden klinischen Befunds (Erkrankung asymptomatisch, mit typischen Symptomen, Endometriosezysten der Ovarien oder Infertilität) analysiert.

Ergebnisse: Mehr als die Hälfte der Patientinnen beurteilten die operative und endokrine Therapie als erfolgreich, besonders in der Gruppe der Frauen mit Schmerzen als vorrangigem Symptom. Bei Infertilität gaben unerwartet mehr als die Hälfte der Frauen an, nichts über den Nutzen von diagnostischen und therapeutischen Maßnahmen der Reproduktionsmedizin zu wissen. Immerhin wurden mehr als 50\% der Frauen mit Infertilität im Laufe der nächsten 2 Jahre nach Diagnosestellung schwanger.

Diskussion: Die Beurteilung und Einschätzung der Erkrankung durch die Patientinnen ist abhängig von Symptomen, dem Zeitpunkt der Diagnose und der individuellen Lebenssituation. Besonders Schmerzen und Aspekte der ungewollten Kinderlosigkeit sollten bei Therapieentscheidungen mitberücksichtigt werden. Eine frühzeitige individuelle und intensivierte Aufklärung vermögen bei betroffenen Frauen die Compliance bez. der Therapie sowie das Verständnis der Erkrankung posi- 
tiv zu beeinflussen und sind essenzieller Bestandteil des klinischen Managements bei Endometriose.

\section{Introduction}

$\nabla$

On average, $8-15 \%$ of women aged $15-50$ years suffer from the typical symptoms and sequelae of endometriosis such as dysmenorrhea, dyspareunia, abdominal and pelvic pain, and infertility [1]. The pathophysiology of this disease and its multiple clinical presentations is still not completely clear. Studies have shown increasing evidence for endometriosis being caused by altered immune responses [2]. Despite the high incidence of endometriosis, its diagnosis is still delayed (on average by 10.4 years) [3]. Diagnostic and therapeutic options for this disease have been recently standardized in national [4] and international consensus statements [5].

Nevertheless, there are only a few studies on women's own perception of the disease and the long-term risks of endometriosis, such as infertility or chronic pain. These aspects were investigated in an Australian study which used focus groups and recruited 61 women suffering from endometriosis. The study showed that patients were mainly concerned with the lack of support and their own daily struggle; patients reported being stressed by the personal losses caused by the disease which affected their family, partnership and career [6]. Women found dealing with endometriosis difficult and time-consuming. After having received sufficient information about the disease, they wanted to be able to decide on the management of their disease and quality of life for themselves. Another analysis by Cox et al. showed that women preferred to take decisions on treatment options such as endoscopic surgery themselves [7].

Endometriosis is a chronic disease which is associated with frequent pain, repeated surgeries, hormone treatment and longterm sequelae such as infertility; it can therefore have an impact on all aspects of a woman's life. A retrospective analysis of healthrelated distress and interference with life activities emphasized the strong impact of frequent pain [8]. Dyspareunia affects the women's partnership, sexual life and fertility, resulting in a reduced quality of life [9]. In a qualitative study of 30 women in Great Britain it was shown that $86 \%$ of women experienced dyspareunia, leading the majority of them to avoid sexual intercourse. Only the desire to become pregnant could motivate these women to endure the pain caused by the disease and be sexually active [9].

The aim of this study was to evaluate patients' perception of endometriosis with regard to treatment strategies and changes in symptoms due to treatment.

\section{Material and Methods}

\section{Patient recruitment}

221 patients with endometriosis were recruited at the Department of Gynecology and Obstetrics of the Technical University of Dresden, Germany. Women diagnosed with endometriosis or adenomyosis between January 2000 and December 2005, irrespective of the actual cause of hospitalization and surgery, were included in this study. Inclusion criteria were macroscopically and histologically confirmed endometriosis or adenomyosis. Age and pre- or postmenopausal status were not inclusion or exclusion parameters. The women were contacted by mail and were asked to return a completed questionnaire. Written consent was obtained from all patients.

\section{Questionnaire}

Questionnaires on symptoms and on pain resulting from endometriosis have recently been developed and are increasingly being used in diagnosis and to control the efficacy of treatment (e.g. endometriosis health profile [10]). Short versions are available as German translations (http://www.endometriose-liga.eu/ files/anamnesebogen.pdf).

As the aim of this study was to evaluate the perception of treatment in four clinical subgroups, a new questionnaire was developed. Due to the concept of the study, there was no initial survey of the health status of participating women prior to treatment. The quantitative questionnaire technique was believed to be appropriate to obtain an insight into individual perspectives of the disease, including subjective assessment of diagnosis, complaints, and therapeutic interventions as well as changes in lifestyle due to endometriosis.

The authors developed a questionnaire and a symptom checklist to collect data. The questionnaire was designed to evaluate the patient's medical history and included diagnostic procedures and symptoms prior to diagnosis and at the time of answering the questionnaire. In addition, initial and ongoing surgical and medical treatment (including frequency, duration and type of treatment) as well as changes in symptoms and fertility and patient's perception of disease and treatment were analyzed. Women in the infertility subgroup were asked about their wish to become pregnant and about what they knew about infertility, diagnostic procedures and infertility treatment. Women who became pregnant were asked about the time interval till becoming pregnant, the birth, weeks of gestation at delivery, and their perception of the effects of treatment. The questionnaire was filled out retrospectively at a mean of 2.7 years after diagnosis. Medical data obtained from clinical records were included in the analysis.

\section{Statistical analysis}

Clinical data of the study population were analyzed. The study population was divided into 4 subgroups depending on the predominant clinical and diagnostic manifestations (infertility, incidental findings, ovarian cysts and pain or symptoms related to

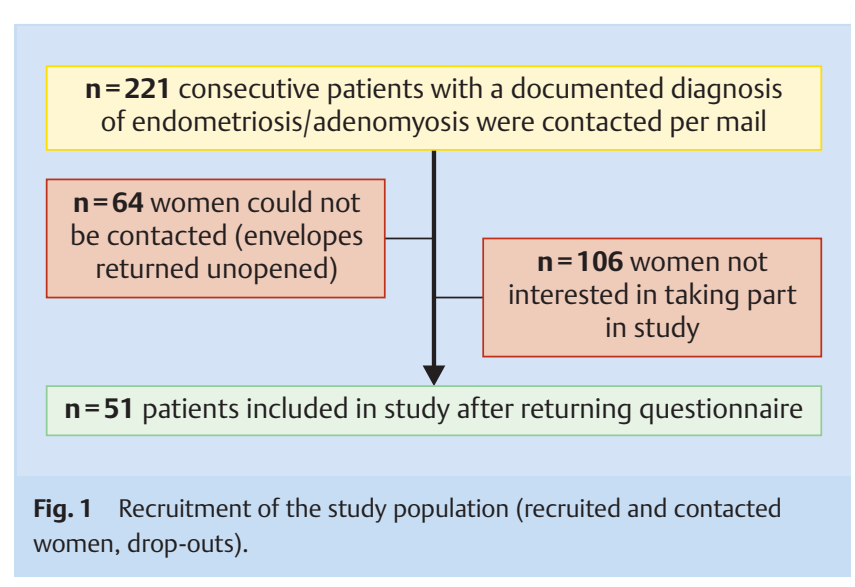


Table 1 Analysis of response rate and median age in different subgroups of patients with endometriosis $\left({ }^{*} \mathrm{p}\right.$-value $\left.<0.05\right)$.

\begin{tabular}{|c|c|c|c|c|c|}
\hline $\begin{array}{l}\text { Main clinical } \\
\text { presentation }\end{array}$ & $\begin{array}{l}\text { All patients } \\
n=221(\%)\end{array}$ & $\begin{array}{l}\text { Median age } \\
\text { (years, STD, range) }\end{array}$ & $\begin{array}{l}\text { Study population } \\
\mathrm{n}=51 \text { (\%) }\end{array}$ & $\begin{array}{l}\text { Median age } \\
\text { (years, STD, range) }\end{array}$ & p-value \\
\hline Infertility & $81(36.7 \%)$ & $30.2 \pm 5.26(17-41)^{*}$ & $19(37.3 \%)$ & $32.2 \pm 5.0(23-41)^{*}$ & 0.034 \\
\hline Incidental findings & $38(17.2 \%)$ & $44.6 \pm 15.0(16-77)^{*}$ & $9(17.6 \%)$ & $47.4 \pm 11.4(31-66)^{*}$ & 0.013 \\
\hline Ovarian cysts & $42(19.0 \%)$ & $37.5 \pm 13.2(16-72)$ & $9(17.6 \%)$ & $31.7 \pm 10.9(16-49)$ & 0.431 \\
\hline $\begin{array}{l}\text { Dysmenorrhea/ } \\
\text { hypermenorrhea }\end{array}$ & $60(27.1 \%)$ & $36.1 \pm 9.4(17-53)$ & $14(27.4 \%)$ & $37.2 \pm 5.7(29-48)$ & 0.644 \\
\hline Total & 221 & $35.6 \pm 11.3(16-77)$ & 51 & $36.2 \pm 9.6(16-66)$ & 0.432 \\
\hline
\end{tabular}

menstruation and sexual intercourse). This subgrouping was performed prior to analysis of the questionnaire based on the coding of the diagnoses (endometriosis and adenomyosis uteri interna) and confirmed by medical chart review. In cases with overlapping symptoms, the main clinical presentation was chosen as the basis for categorization.

The statistical significance of differences between studied subgroups was assessed using Pearson's $\mathrm{X}^{2}$-Test and the standardized residual method. Differences in median values were compared by nonparametric Mann-Whitney test. Significance was defined as $\mathrm{p} \leq 0.05$.

\section{Results \\ $\nabla$}

\section{Description of study population}

The rate of return for the questionnaires was 51/157 (32.5\%) ( Fig. 1). In spite of the relatively low response rate, the proportion of returned questionnaires for the subgroups was comparable to the distribution of the subgroups in the whole study population (Table 1). When we compared the subgroups, women in the subgroups 'infertility' and 'incidental findings/asymptomatic' differed significantly with regard to age. The higher median age was due to the study's recruitment strategy of including women of all ages with histological findings of endometriosis and adenomyosis. The oldest patient who answered the questionnaire was 66 years old and was in the group of incidental findings. The indication for vaginal hysterectomy was incontinence, and adenomyosis uteri was confirmed histologically. The age of the oldest women with a histological diagnosis of endometriosis, but not adenomyosis uteri interna, was 48 .

The completed questionnaires and the clinical data of 51 women were analyzed in this study. The following clinical parameters were assessed using the clinical charts of the study population: diagnosis, complaints, treatments received, medical history, deliveries, abortions, ectopic gravidity, organ manifestations, stage of endometriosis according to the revised classification for endometriosis of the American Society for Reproductive Medicine (rASRM-score) [10], histology, surgical intervention, and further recommended treatment. The clinical data of the study population based on medical records are shown in $\bullet$ Table 2 .

\section{Differences in symptoms and diagnostic methods} in different subgroups

The questionnaires were analyzed for the four clinical subgroups. Although the numbers in some groups were small, significant differences were observed ( Table 3). Allocation to clinical subgroups corresponded to self-reported symptoms. Dysmenorrhea, the most typical symptom of endometriosis, was reported for almost $80 \%$ of the patients in the symptomatic group, for one in every three women with infertility, and for one in every two women with ovarian endometriosis. 3/9 women without typical symptoms reported pelvic pain but no dysmenorrhea.

The patients were questioned about the reasons their gynecologist had suspected and diagnosed endometriosis. There were no statistical differences between subgroups. Vaginal ultrasound led to the diagnosis of endometriosis or adenomyosis in a higher percentage of the group with ovarian endometriosis and in the asymptomatic group, but the difference was not statistically significant. In the infertility subgroup, the most common diagnostic method was laparoscopy.

\section{Differences in endocrine treatment \\ between different subgroups}

The incidence of endocrine treatment for endometriosis was comparable for all groups but was especially high in the infertility group. A tendency, which was not statistically significant, was found for women in the infertility group to be treated with gonadotropin-releasing hormone analogues (GnRH agonists). The use of GnRH agonists across all groups was quite high at $58.8 \%$, because the study was conducted before progestin-only medication for patients with endometriosis was introduced in Germany in 2010.

Women reported relief of symptoms after endocrine treatment in the infertility and the typical symptom groups (52.6 and $33.3 \%$ of women, respectively). Significantly fewer women in the asymp-

Table 2 Characteristics of the study population.

\begin{tabular}{|c|c|}
\hline Characteristics & $\begin{array}{l}\text { Study population } \\
(\mathrm{n}=51)\end{array}$ \\
\hline Average age in years (range) & $36.2(16-66)$ \\
\hline \multicolumn{2}{|l|}{ Marital status } \\
\hline married/partnership (\%) & $39(76.5)$ \\
\hline single (\%) & $12(23.5)$ \\
\hline Mean parity (range) & $1.3(0-5)$ \\
\hline - miscarriage $(\%)$ & $5(9.8)$ \\
\hline ectopic pregnancy & $2(3.9)$ \\
\hline \multicolumn{2}{|c|}{ Clinical grading of endometriosis [rASRM score] (\%) } \\
\hline - rASRMI & $17(33.3)$ \\
\hline D rASRMII & $7(13.7)$ \\
\hline - rASRM III & $12(23.5)$ \\
\hline - rASRMIV & $3(5.9)$ \\
\hline Adenomyosis & $13(25.5)$ \\
\hline \multicolumn{2}{|l|}{ Documented proposed further treatment (\%) } \\
\hline $\begin{array}{l}\text { endocrine treatment with gonadotropin } \\
\text { releasing hormone }\end{array}$ & $26(50.1)$ \\
\hline - endocrine treatment with progestins & $16(31.4)$ \\
\hline hysterectomy & $2(3.9)$ \\
\hline assisted reproductive medicine & $4(7.8)$ \\
\hline
\end{tabular}


Table 3 Self-reporting questionnaire $\left(\mathrm{n}=51\right.$ women); statistical analysis using standardized residuals (values in italics) $\left({ }^{*}\right.$ significant difference, $\left.\mathrm{p}<0.05\right)$.

\begin{tabular}{|c|c|c|c|c|c|c|}
\hline & & $\begin{array}{l}\text { Infertility } \\
(n=19)\end{array}$ & $\begin{array}{l}\text { Incidental } \\
\text { findings }(n=9)\end{array}$ & $\begin{array}{l}\text { Ovarian cyst } \\
(n=9)\end{array}$ & $\begin{array}{l}\text { Clinical symptoms } \\
(n=14)\end{array}$ & p-value \\
\hline \multirow{8}{*}{$\begin{array}{l}\text { Complaints before } \\
\text { treatment }\end{array}$} & \multirow[t]{2}{*}{ pelvic pain } & $10(52.6)$ & $3(33.3)$ & $4(44.4)$ & $9(64.3)$ & \multirow[t]{2}{*}{0.515} \\
\hline & & 0.1 & -0.7 & -0.3 & 0.7 & \\
\hline & \multirow[t]{2}{*}{ dysmenorrhea } & $7(36.8)$ & $0(0.0)^{*}$ & $5(55.6)$ & $11(78.8)$ & \multirow[t]{2}{*}{0.002} \\
\hline & & -0.5 & -2 & 0.5 & 1.9 & \\
\hline & \multirow[t]{2}{*}{ - hypermenorrhea } & $9(47.4)$ & $0(0.0)$ & $3(33.3)$ & $13(92.9)^{*}$ & \multirow[t]{2}{*}{0.0001} \\
\hline & & -0.1 & -2.1 & -0.7 & 2.3 & \\
\hline & \multirow{2}{*}{$\begin{array}{l}\text { premenstrual } \\
\text { symptoms }\end{array}$} & $5(26.3)$ & $1(11.1)$ & $2(22.2)$ & $9(64.3)^{*}$ & \multirow[t]{2}{*}{0.030} \\
\hline & & -0.5 & -1.2 & -0.6 & 2 & \\
\hline \multirow{2}{*}{\multicolumn{2}{|c|}{ Median rASRM score (1-4) }} & 2.1 & 2 & 2.1 & 1.5 & \multirow[t]{2}{*}{0.403} \\
\hline & & 0.8 & 0.9 & 0.4 & 0.3 & \\
\hline \multirow{2}{*}{\multicolumn{2}{|c|}{ Adenomyosis ( $\mathrm{n}$ ) }} & 2 & 6 & 1 & 4 & \multirow[t]{2}{*}{0.110} \\
\hline & & -0.1 & -1.3 & -0.9 & 0.1 & \\
\hline \multirow{8}{*}{$\begin{array}{l}\text { Diagnostic } \\
\text { assessment }\end{array}$} & \multirow[t]{2}{*}{ - typical symptoms } & $3(15.8)$ & $2(22.2)$ & $0(0.0)$ & $5(35.7)$ & \multirow[t]{2}{*}{0.194} \\
\hline & & -0.4 & 0.2 & -1.3 & 1.4 & \\
\hline & - gynecological & $4(21.1)$ & $1(11.1)$ & $1(11.1)$ & $3(21.4)$ & 0.845 \\
\hline & examination & 0.4 & -0.5 & -0.5 & 0.3 & \\
\hline & - vaginal ultrasound & $6(31.6)$ & $4(44.4)$ & $4(44.4)$ & $3(21.4)$ & 0.589 \\
\hline & & -0.1 & 0.6 & 0.6 & -0.8 & \\
\hline & - laparoscopy & $16(84.2)$ & $1(11.1)^{*}$ & $3(33.3)$ & $10(71.4)$ & 0.001 \\
\hline & & 1.4 & -1.9 & -1 & 0.6 & \\
\hline Therapeutic & - laparoscopy & $18(94.7)$ & $2(22.2)$ & $7(77.8)$ & $12(85.7)$ & 0.0001 \\
\hline interventions & & 0.9 & -1.9 & 0 & 0.4 & \\
\hline & - laparotomy & $5(26.3)$ & $0(0.0)$ & $4(44.4)$ & $0(0.0)$ & 0.016 \\
\hline & & 0.9 & -1.3 & 1.9 & -1.6 & \\
\hline & - hysteroscopy & $0(0.0)$ & $1(11.1)$ & $0(0.0)$ & $2(14.3)$ & 0.419 \\
\hline & & -1.1 & 0.6 & -0.7 & 1.3 & \\
\hline & - hysterectomy & $5(26.3)$ & $3(33.3)$ & $1(11.1)$ & $6(42.9)$ & 0.158 \\
\hline & & -0.2 & 0.2 & -1 & 0.9 & \\
\hline & - oral contraception & $5(26.3)$ & $0(0.0)$ & $4(44.4)$ & $5(35.7)$ & 0.108 \\
\hline & & -0.1 & -1.6 & 1 & 0.6 & \\
\hline & - GnRH agonists & $15(78.9)$ & $3(33.3)$ & $5(55.6)$ & $7(50.0)$ & 0.541 \\
\hline & & 1.1 & -1 & -0.1 & -0.4 & \\
\hline Complaints after ini- & pelvic pain & $6(31.6)$ & $2(22.2)$ & $0(0.0)$ & $4(28.6)$ & 0.301 \\
\hline tiation of treatment & & 0.7 & -0.1 & -1.5 & 0.4 & \\
\hline & - dysmenorrhea & $1(5.3)$ & $1(11.1)$ & $1(11.1)$ & $2(14.3)$ & 0.850 \\
\hline & & -0.6 & 0.1 & 0.1 & 0.5 & \\
\hline & - hypermenorrhea & $1(5.3)$ & $1(11.1)$ & $0(0.0)$ & $4(28.6)$ & 0.598 \\
\hline & & -0.4 & 0.4 & -0.8 & 0.9 & \\
\hline & - premenstrual & $1(5.3)$ & $1(11.1)$ & $0(0.0)$ & $2(14.3)$ & 0.598 \\
\hline & symptoms & -0.4 & 0.4 & -0.8 & 0.9 & \\
\hline Subjective changes & - no change & $6(31.6)$ & $3(33.3)$ & $1(11.1)$ & $5(35.7)$ & 0.131 \\
\hline due to surgery & & 0.2 & 0.2 & -1 & 0.4 & \\
\hline & - improvement & $13(68.4)$ & $6(66.7)$ & $6(66.7)$ & $7(50.0)$ & \\
\hline & & 0.3 & 0.1 & 0.1 & -0.6 & \\
\hline & - symptoms worse & $0(0.0)$ & $0(0.0)$ & $0(0.0)$ & $2(14.3)$ & \\
\hline & & -1.2 & -0.8 & 1.5 & 0.9 & \\
\hline Subjective changes & - no change & $8(42.1)$ & $7(77.8)$ & $4(44.4)$ & $11(78.6)$ & 0.113 \\
\hline with medication & & -1 & 0.7 & -0.6 & 1 & \\
\hline & - improvement & $10(52.6)$ & $1(11.1)$ & $3(33.3)$ & $2(14.3)$ & \\
\hline & & 1.7 & -1.1 & 0.1 & -0.3 & \\
\hline & symptoms worse & $1(5.3)$ & $1(11.1)$ & $2(22.2)$ & $1(7.1)$ & \\
\hline & & -0.6 & 0.1 & 1.2 & -0.3 & \\
\hline Perception of & - surgery is beneficial & $15(78.9)$ & $7(77.8)$ & $7(77.8)$ & $8(57.1)$ & \\
\hline & $\begin{array}{l}\text { endocrine treatment } \\
\text { is beneficial }\end{array}$ & $12(63.2)$ & $1(11.1)^{*}$ & $5(55.5)$ & $8(57.1)$ & \\
\hline & $\begin{array}{l}\text { - diagnosis of infertility - } \\
\text { I don't know }\end{array}$ & $9(47.4)$ & 0 & 0 & $2(14.3)$ & 0.511 \\
\hline $\begin{array}{l}\text { Infertility-specific } \\
\text { diagnosis/treatment }\end{array}$ & $\begin{array}{l}\text { diagnostic } \\
\text { sperm count }\end{array}$ & $13(68.4)$ & & & & \\
\hline & - insemination & $5(26.3)$ & & & & \\
\hline & - in-vitro fertilization & $4(21.1)$ & & & & \\
\hline & $\begin{array}{l}\text { intracytoplasmatic } \\
\text { sperm injection }\end{array}$ & $3(15.8)$ & & & & \\
\hline
\end{tabular}


tomatic group with predominantly confirmed adenomyosis (6 of 9 women) considered endocrine treatment to be beneficial ( Table 4). The reported symptoms (dysmenorrhea, heavy vaginal bleeding and premenstrual symptoms) particularly improved in the symptomatic group. No statistical differences were found between the 4 subgroups after initiation of treatment, although clinical differences were statistically significant prior to treatment. 11/14 patients with symptoms did not recall changes due to medication.

\section{Differences in surgical treatment \\ between different subgroups}

Unexpectedly, 5/19 women with infertility reported that hysterectomy had been proposed to them to treat endometriosis in spite of their initial and documented wish to have a child. Two women suffering from pain and hypermenorrhea received initial treatment with hysterectomy after unsuccessful infertility treatment. Surgery was performed in these women because of severe dysmenorrhea and their strong desire for a definitive treatment of endometriosis. One 33-year-old woman underwent multiple unsuccessful IVF treatments and finally adopted a child. Because of the severe impairment of her quality of life she underwent hysterectomy and bilateral oophorectomy. Another 3 women underwent hysterectomy within 2 years after diagnosis.

In all subgroups, more than $50 \%$ of the patients stated that their symptoms improved post surgery. Two women stated that symptoms worsened after surgery, one in the group with ovarian cysts and one in the group with clinical symptoms; both women had no additional hormone treatment.

\section{Differences in perception of treatment options between different subgroups}

The questionnaire included the subjective perception of possible treatment effects. The women were asked to complete multiple choice questions. More than $75 \%$ women reported a perceived effect of surgery. Only in the symptomatic group did fewer women consider surgery to be a beneficial treatment for endometriosis (8/14). Three women stated that only endocrine treatment was beneficial and another 3 believed that no treatment was beneficial. Of the 9 women who believed that endocrine treatment is not beneficial, 2 were facing infertility and 4 were in the subgroup with asymptomatic endometriosis. Only one woman with dysmenorrhea stated that endocrine treatment was not beneficial; she also suffered from infertility. 23 women had confirmed dysmenorrhea prior to treatment. OTable 4 shows the perception of endocrine treatment and surgery for these 23 women.

\section{Knowledge of patients about infertility}

and the success of intervention

12 of the 19 women with endometriosis and infertility recalled undergoing functional testing of the tubes; 7 reported having attempted several methods of artificial reproductive medicine. Interestingly, 9 of 19 women facing infertility responded to the question about what they thought of the diagnosis and treatment of infertility with "I don't know" (47.4\%).

$11 / 19$ women in the infertility group reported a pregnancy after receiving a diagnosis of endometriosis. The time to pregnancy was less than 2 years in 9 of these women. Four of the 11 women became pregnant with artificial reproduction methods. Three women who underwent in-vitro fertilization or intracytoplasmatic sperm injection did not achieve a pregnancy by the time this survey was completed.
Table 4 Effect of treatment: statements of women with self-reported symptoms of dysmenorrhea prior to treatment ( $n=19 ; 4$ out of 23 patients did not respond).

\begin{tabular}{|c|c|c|c|}
\hline & $\begin{array}{l}\text { Surgical } \\
\text { treatment } \\
\text { beneficial }\end{array}$ & $\begin{array}{l}\text { Surgical } \\
\text { treatment NOT } \\
\text { beneficial }\end{array}$ & $\begin{array}{l}\text { No } \\
\text { comment }\end{array}$ \\
\hline $\begin{array}{l}\text { Endocrine treatment } \\
\text { beneficial }\end{array}$ & 12 & 2 & 1 \\
\hline $\begin{array}{l}\text { Endocrine treatment } \\
\text { NOT beneficial }\end{array}$ & 1 & & \\
\hline No comment & 3 & & \\
\hline
\end{tabular}

\section{Discussion \\ $\nabla$}

Endometriosis is a chronic disease with many clinical manifestations. The subjective perception of the disease was assessed by a questionnaire-based survey which compared three symptomatic subgroups with endometriosis and an asymptomatic group of women who had an incidental diagnosis of endometriosis.

The women in the infertility group were significantly younger than women in the other groups. The asymptomatic group had a higher age at the first diagnosis of endometriosis/adenomyosis uteri interna. In spite of the pre-categorization into 4 subgroups there were no significant differences in rASRM score, although the rASRM score tended to be lower in the asymptomatic group. This finding corresponds to the literature where a reversed score has been proposed by the American Society of Reproductive Medicine as a classification model for the severity of endometriosis; however, it still correlates only poorly with pain and sterility $[11,12]$. There were no cases of severe, deep, infiltrating endometriosis involving the bladder and colorectum in our study.

Infertility is correlated with endometriosis and vice versa, although the pathophysiological mechanisms for this correlation are still not clear [13]. Clinical records revealed that endometriotic cysts were found in more than $50 \%$ of the patients in the infertility group, a significantly higher percentage than in the asymptomatic group. It is still not clear whether endometriotic cysts have a direct negative influence on fertility or whether they only lead to impaired ovarian reserve due to surgery. The indication for cyst excision must therefore be evaluated carefully for each patient [14].

The medical approach to treat endometriosis consists of different hormone treatment options. The capacity of oral contraceptives, local or systemic progestins, or GnRH agonists to reduce endometriosis-related pain is well proven. The high proportion of women treated with GnRH agonists in this study can be explained by the absence of an approved progestagen for endometriosis in the study period.

Even though clinical symptoms differed significantly in the preselected subgroups prior to treatment, the evaluation of patients' perception of the disease and treatment only showed a few significant differences between groups after initiation of treatment. Significant differences were only found for self-reported symptoms, especially dysmenorrhea and other menstrual symptoms. Interestingly, after initiation of treatment with surgery and additional proposed medical treatment, the groups no longer differed with regard to symptoms. No other statistical differences were found overall with regard to the effects of surgery and medical treatment, but a significantly lower belief in the beneficial effect of endocrine treatment was reported for the asymptomatic 
group. This can be easily attributed to a lack of any subjective benefit from medication. In contrast, a high percentage (12/19) of women with prior dysmenorrhea reported that combined endocrine and surgical treatment was beneficial.

10/19 of women with infertility reported an improvement of symptoms with endocrine treatment. These women were in favor of hormone treatment, even though medication prolonged the time to pregnancy. Nevertheless, $50 \%$ of women with infertility reported becoming pregnant within 2 years after medical treatment. The perceived positive effect of hormone treatment and subsequent pregnancy led to the high retrospective assessment of endocrine treatment as "beneficial". This positive assessment of hormone treatment (oral contraceptives, progestin only or GnRH agonists) in the infertility group may be interpreted as a good understanding of the pathophysiological condition of endometriosis. Women in this group may have been influenced by the reduction of pain and the reduced risk of recurrence of endometriosis, which allowed women to postpone their wish to become pregnant.

The high proportion of infertile women treated with GnRH analogues despite having only mild endometriosis reflects the usual procedure at the time of the survey. Based on strong evidence (recommendation grade A), current guidelines do not recommend the prescription of GnRH agonists to infertile women with minimal or mild endometriosis [5].

Women with a documented diagnosis of endometriosis and/or adenomyosis were included in this analysis. Age was not defined as an inclusion or an exclusion criterion; a small subgroup of women was therefore above 50 years of age and was postmenopausal $(n=5)$. Four of these women were in the subgroup with incidental findings, and all of them had adenomyosis. Although the number of older women is too small to draw any conclusions, it is important to underline the fact that endometriosis/adenomyosis may also be present in postmenopausal women, as noted recently in a retrospective analysis [15].

It is worth mentioning hysterectomy as a treatment option for endometriosis, even for infertility patients; hysterectomy was initially used in 2/19 of women and subsequently in a further 3 women. These women were aged 33-43 years and had undergone many years of infertility treatment. Hysterectomy was the final treatment option for endometriosis in spite of the women's infertility.

Traditionally, hysterectomy and oophorectomy have been considered an effective treatment option, especially in women with endometriosis involving the uterus [16]. Hysterectomy without oophorectomy is sufficient for adenomyosis uteri interna, but not for endometriosis in general [17], even if a woman, possibly due to a misunderstanding of the pathophysiology of endometriosis, asks for this intervention. If the woman suffers from severe symptoms, other treatment options are ineffective and fertility is no longer desired, the indication for hysterectomy with or without oophorectomy in women with endometriosis should be made based on an individual risk-benefit evaluation and a decision-making consensus $[18,19]$.

Seven out of 19 infertility patients used an artificial reproduction method, and $50 \%$ of all women with infertility became pregnant within 2 years after the first diagnosis as a result. Half of the women with infertility reported that they could not decide on the value of diagnostic and therapeutic infertility treatments ("I do not know"). This finding shows the importance of adequate education about the special nature of endometriosis. The importance of a biopsychosocial approach to pain was recently empha- sized by Siedentopf et al. [20]. Adapted counseling techniques are needed for doctors and patients to understand the nature of endometriosis as a complex chameleonic disease and the effect of treatment.

Nevertheless, the experience with certified endometriosis centers in Germany shows that complex treatment options for patients should be discussed individually in specialized interdisciplinary boards [21].

A limitation of the study was the small number of participating women. The quantitative questionnaire was sent by mail to 221 women; 64 of them could not be reached and the envelope was returned, possibly because of a change of address. All women were only contacted by mail and could opt not to answer by not returning the questionnaire to the clinic or returning an uncompleted questionnaire. This led to an unexpectedly low return rate of $32.5 \%$, although the usual return rate of about $40-50 \%$ had been expected. Fortunately, mean age and proportional subgrouping into the four clinical groups were comparable with the initially intended study sample.

The self-reporting of symptoms, the treatment and the changes associated with treatment (mean interval between the first treatment and completion of the questionnaire was about 2-3 years) may have led to distorted and possibly false memories. This study can therefore not serve as a study on compliance with proposed treatment. Nevertheless, future studies on this aspect of endometriosis are needed.

The design of this study with a newly developed questionnaire was only appropriate for quantitative research done in a small study sample. Qualitative research to clarify the perception of endometriosis is needed, using structured interview techniques or a focus group design.

Modern information technologies allow women to obtain medical information and exchange medical information via the internet. This means of communication in patient communities has been described in detail for endometriosis-support groups in Canada [22]. Modern media and social networks should be used for research and as a way to reach a broad range of women with endometriosis.

\section{Conclusion}

It is difficult to understand what endometriosis means to women suffering from this disease, as it can have many different clinical manifestations. This questionnaire-based survey analyzed four clinical subgroups and showed that women with endometriosis demonstrate different responses to symptoms and treatment, even if these differences were not statistically significant. It is obvious that symptoms and perceptions of each woman may vary, leading to the conclusion that personalized and intensive counseling is extremely important.

\section{Conflict of Interest}

$\nabla$

None. 


\section{References}

1 Schweppe KW. Differentialdiagnose und Behandlungsstrategien bei Endometriose: Was tun - wann? Journal für Fertilität und Reproduktion 2003; 13: 8-12

2 Slabe N, Meden-Vrtovec H, Verdenik I et al. Cytotoxic T-cells in peripheral blood in women with endometriosis. Geburtsh Frauenheilk 2013; 73: $1042-1048$

3 Hudelist G, Fritzer N, Thomas A et al. Diagnostic delay for endometriosis in Austria and Germany: causes and possible consequences. Hum Reprod 2012; 27: 3412-3416

4 Ulrich $U$, Buchweitz O, Greb R et al. Interdisciplinary S2k guidelines for the diagnosis and treatment of endometriosis: short version - AWMF Registry No. 015-045, August 2013. Geburtsh Frauenheilk 2013; 73 : 890-898

5 Johnson NP, Hummelshoj L; World Endometriosis Society Montpellier Consortium. Consensus on current management of endometriosis. Hum Reprod 2013; 28: 1552-1568

6 Cox H, Henderson L, Andersen N et al. Focus group study of endometriosis: struggle, loss and the medical merry-go-round. Int J Nurs Pract 2003; 9: 2-9

7 Cox H, Henderson L, Wood R et al. Learning to take charge: women's experiences of living with endometriosis. Complement Ther Nurs Midwifery 2003; 9: 62-68

8 Mathias SD, Kuppermann M, Liberman $R$ et al. Chronic pelvic pain: prevalence, health-related quality of life and economic correlates. Obst Gynecol 1996; 87: 321-327

9 Denny E, Mann $\mathrm{CH}$. Endometriosis-associated dyspareunia: the impact on women's lives. J Fam Plann Reprod Health Care 2007; 33: 189-193

10 Jones $G$, Jenkinson C, Kennedy S. Evaluating the responsiveness of the endometriosis health profile questionnaire: the EHP-30. Qual Life Res 2004; 13: 705-713

11 Haas D, Shebl O, Shamiyeh A et al. The rASRM score and the Enzian classification for endometriosis: their strengths and weaknesses. Acta Obstet Gyn Scand 2013; 92: 3-7
12 Ulrich U, Hucke J, Schweppe K-W. Empfehlung zur Diagnostik und Therapie der Endometriose. Zentralbl Gynakol 2005; 127: 338-345

13 Vercellini P, Trespidi L, De Giorgi $O$ et al. Endometriosis and pelvic pain: relation to disease stage and localization. Fertil Steril 1996; 65: 299304

14 Rimbach S, Ulrich U, Schweppe KW. Surgical therapy of endometriosis: challenges and controversies. Geburtsh Frauenheilk 2013; 73: 918923

15 de Ziegler D, Borghese B, Chapron C. Endometriosis and infertility: pathophysiology and management. Lancet 2010; 376: 730-738

16 Haas D, Chvatal R, Reichert B et al. Endometriosis: a premenopausal disease? Age pattern in 42,079 patients with endometriosis. Arch Gynecol Obstet 2012; 286: 667-670

17 Kissler S, Gaetje R, Siebenzehnruebl E et al. Neues in Diagnostik und Therapie der Endometriose. Zentralbl Gynakol 2004; 126: 299-302

18 Halis G, Kopf A, Mechsner S et al. Schmerztherapeutische Optionen bei Endometriose. Dtsch Arztebl 2006; 103: A-1146/B-968/C-933

19 Lefebre G, Allaire C, Jeffrey J et al.; Clinical Practice Gynaecology Committee; Executive Committee and Council, Society of Obstetricians and Gynaecologists of Canada. SOGC clinical guidelines. Hysterectomy. J Obstet Gynaecol Can 2002; 24: 37-61

20 Siedentopf F, Hausteiner-Wiehle C. S3 Guideline "Management of patients with non-specific, functional and somatoform physical complaints" - What is important for gynaecological practice? Geburtsh Frauenheilk 2013; 73: 224-226

21 Ebert $A D$, Ulrich $U$, Keckstein J et al. Implementation of certified endometriosis centers: 5 -year experience in German-speaking Europe. Gyn Obstet Invest 2013; 76: 4-9

22 Whelan E. 'No one agrees except for those of us who have it': endometriosis patients as an epistemological community. Sociol Health Illn 2007; 29: 957-982 